\title{
A LEITURA PESSOAL DE LITERATURA NA ESCOLA COMO POSSIBILIDADE DE FORMAÇÃO DO LEITOR: CONTRIBUIÇÕES DA LEITURA SUBJETIVA
}

\section{PERSONAL READING OF LITERATURE IN SCHOOL AS A POSSIBILITY FOR THE FORMATION OF THE READER: CONTRIBUTIONS OF THE SUBJECTIVE READING}

\author{
Cláudia de Oliveira Daibello ${ }^{1}$ \\ Cláudia Beatriz de C. N. Ometto ${ }^{2}$
}

\begin{abstract}
Resumo: O presente texto apresenta o recorte de uma pesquisa mais ampla, que busca compreender práticas de leitura de literatura realizadas no contexto escolar e também apontar possibilidades para um trabalho com literatura na escola com foco na experiência pessoal da criança com o texto literário. Neste texto, temos como objetivo apresentar as contribuições da perspectiva didática proposta por autores franceses, como Rouxel (2012, 2013), e nomeada como Leitura Subjetiva.
\end{abstract}

Palavras-chave: Leitura de literatura; leitura na escola; leitura subjetiva.

\begin{abstract}
This text presents the outline of a broader research, which seeks to understand literature reading practices in the school context and also to point possibilities for work with literature in school with focus on the child's personal experience with literary text. In this text, we aim to present the contributions from the didactic perspective proposed by French authors, such as Rouxel (2012, 2013), and named as Subjective Reading.
\end{abstract}

Keywords: Literature reading; reading in school; subjective reading.

\section{À guisa de introdução}

O texto a seguir apresenta um recorte da pesquisa de doutorado, que vem sendo desenvolvida através do grupo ALLE-AULA ${ }^{3}$, da Faculdade de Educação da Universidade Estadual de Campinas (Unicamp), e que tem como objetivo compreender como se realiza a leitura de literatura em uma escola pública de Ensino Fundamental, além de refletir sobre as condições necessárias a essa prática no contexto escolar, de modo a favorecer a experiência pessoal da criança com o texto literário, condição que consideramos essencial na formação do sujeito leitor.

Embora a questão da leitura no contexto escolar seja insistentemente abordada através de diversas perspectivas na área de educação, observamos na revisão bibliográfica realizada para a pesquisa que o foco desses estudos quase sempre está voltado à questão da aquisição da leitura ou ao desenvolvimento de competências relacionadas à compreensão de textos, frequentemente tratando-se este aspecto de forma associada à formação do leitor. A questão da leitura de literatura na escola, porém, permanece quase sempre à margem especialmente quando se trata de abordagens que valorizem o leitor e sua experiência com esse tipo de texto.

Esta lacuna está relacionada, a nosso ver, à especificidade do texto literário e à consequente particularidade do tipo de leitura que se realiza quando se lê um livro de literatura, muito distante das práticas realizadas no cotidiano escolar.

\footnotetext{
${ }^{1}$ Secretaria Municipal de Educação de Santa Bárbara d' Oeste - SP.

${ }^{2}$ FE-UNICAMP.

${ }^{3}$ Alfabetização, Leitura, Escrita e Trabalho Docente na Formação Inicial.
} 
$\mathrm{Na}$ rotina da escola, as atividades são organizadas de forma a atender às finalidades pedagógicas voltadas ao ensino-aprendizagem de competências e habilidades ${ }^{4}$, entre elas, a de leitura. Na sala de aula, a prática de leitura - mesmo a de literatura - ocorre pautada pela restrição de sentidos, na qual todos devem compreender de uma única maneira para, em geral, dar uma mesma resposta para determinados questionamentos sobre os textos.

Por outro lado, no caso da leitura literária que se realiza socialmente, o movimento é inverso, ainda que não sejam válidos todos e quaisquer sentidos, uma vez que o texto tem um contexto histórico e temporal de produção, a leitura da literatura permite a expansão de sentidos por parte do leitor e a construção de um significado para $s i^{5}$.

Tal problemática não é certamente uma exclusividade das reflexões em relação às escolas brasileiras. Na França, por exemplo, ao analisar as propostas de trabalho com literatura presentes nos documentos oficiais das últimas décadas, Rouxel (2012) ressalta que, apesar das diferenças entre elas, todas apresentam uma concepção de leitura de total submissão do leitor ao texto, desconsiderando o leitor real e promovendo um tipo de leitura consensual e pré-estabelecida. Para a autora, tais propostas não permitem um espaço para a interpretação ou julgamento pessoal, desconsiderando a dimensão subjetiva da leitura, essencial quando se trata da leitura do texto literário.

Segundo a autora, é apenas a partir de 2001, no contexto francês, que a proposta de um ensino de literatura voltado ao leitor começa a ser incentivada pelos programas oficiais, através do que se denominou de "leitura cursiva": um tipo de leitura previsto como uma forma livre, direta e corrente, com foco em apreender o sentido a partir do todo. Rouxel (2012, p. 276) defende essa proposta como uma nova perspectiva no trabalho com literatura na escola: "Leitura autônoma e pessoal, ela autoriza o fenômeno de identificação e convida a uma apropriação singular ${ }^{6}$ das obras. Favorecendo outra relação com o texto, significa um desejo de levar em conta os leitores reais".

No contexto brasileiro, encontramos atualmente experiências pontuais relatadas em pesquisas acadêmicas, que buscam valorizar esse leitor real e colocar em pauta propostas de uma leitura pessoal $^{7}$ de literatura na escola. Ao que nos parece, porém, estas pesquisas representam iniciativas individuais, que não refletem, em geral, o trabalho com leitura de literatura no contexto escolar.

No âmbito editorial, alguns autores também vêm se dedicando a refletir sobre tais ideias no contexto nacional com a divulgação de estudos e tradução de textos estrangeiros, principalmente franceses, como é o caso da obra recentemente produzida por Rouxel, Langlade

\footnotetext{
${ }^{4}$ Nossa concepção de habilidades e competências não compactua com o que geralmente se apresenta nos documentos oficiais, nos quais esses termos estão relacionados quando se trata de práticas de leitura. Ou seja, não compactuamos com as capacidades compreendidas pelas teorias da inteligência e do desenvolvimento humano como competências, tampouco com as teorias do comportamento e da aprendizagem entendidas como habilidades. Consideramos, a partir da perspectiva histórico-cultural desenvolvida por Vigotski (1998), que as funções mentais não são fixas e imutáveis, mas sim moldadas no curso da história dos sujeitos pela mediação da cultura e do outro, ou seja, tais competências e habilidades poderiam ser entendidas como funções que se desenvolvem culturalmente a partir das relações eu/outro.

${ }^{5}$ Ao utilizarmos esse termo, é importante ressaltar que, a partir dos pressupostos teóricos da abordagem históricocultural do desenvolvimento humano e na perspectiva enunciativo-discursiva, sustentamos a proposição da constituição social do sujeito em contraposição a uma abordagem idealista ou psicológica da subjetividade humana, questão sobre a qual discorreremos mais detalhadamente a seguir.

${ }^{6}$ Esse termo, bastante utilizado pelos autores franceses, refere-se à apropriação pessoal do leitor, no sentido de considerar os leitores reais (e não um leitor conceitual), tendo como pressuposto a intersubjetividade.

${ }^{7}$ Embora, na tradução dos textos franceses, a utilização de termos como leitura subjetiva, leitura singular e leitura pessoal apareça sem distinção ente si, em nossa pesquisa, sempre que o contexto permitiu, optamos pela escolha da expressão leitura pessoal ou experiência pessoal de leitura, reconhecendo que este termo representa melhor a concepção com a qual trabalhamos e minimiza equívocos em relação a uma concepção de leitura como criação de um sujeito apartado das condições concretas de recepção.
} 
e Rezende (2013) e algumas iniciativas editoriais que realizaram a tradução para o português de autores como Petit $(2009,2013)$.

Já em relação às orientações educacionais em âmbito estadual e federal, observamos que há uma tentativa de valorização do leitor nos documentos oficiais, as quais demonstram um alinhamento com estas perspectivas vindas de fora, porém, isso ainda ocorre de forma generalista e superficial, dificultando modificações significativas na prática pedagógica, uma vez que a potencialidade dessa abordagem ainda é pouco esclarecida e acaba passando desapercebida.

A realidade é que tal perspectiva, a nosso ver, está ainda circunscrita a iniciativas pontuais, tendo pouquíssima repercussão nas práticas escolares, o que pode ser atribuído, em grande parte, à imensa preocupação a que estão submetidos professores e gestores, no que se refere aos índices de proficiência de leitura e desempenho dos alunos em avaliações institucionais, cujos resultados, infelizmente, parecem levar a um trabalho com leitura focado estritamente nas competências e habilidades cognitivas necessárias ao ato de ler, em detrimento de uma formação que privilegie uma experiência pessoal de leitura.

\section{O papel do leitor nas teorias da leitura}

Em grande parte, essa relutância em reconhecer o papel do leitor no ato de ler advém das próprias teorias da leitura, que passaram a considerar o leitor como tendo um papel central na atribuição de sentidos do texto apenas a partir da década de 60, através das discussões motivadas pela teoria da Estética da Recepção. A partir desse período, vários estudos dedicaram-se a compreender o papel desse leitor, ora outorgando-lhe uma liberdade controlada, ora considerando-o como detentor absoluto dos significados (como se não houvesse nada no texto em si para ser interpretado e tudo fosse submetido à sua criação).

Segundo Eagleton (2006, p. 126), na tentativa de explicar o sistema de regras e as lacunas de sentido, que permitiam o posicionamento do leitor diante de um texto, em geral, as teorias da leitura acabaram reduzindo-o a uma função deste, como uma estrutura abstrata e impessoal que desconsiderava o sujeito leitor. Desse modo, estas teorias ignoraram, cada qual a seu modo, a posição do leitor na história. Conforme alerta o autor, "os leitores não se encontram com os textos no vácuo: todos os leitores estão social e historicamente situados, e a maneira pela qual interpretam as obras literárias será profundamente condicionada por este fato" (EAGLETON, 2006, p. 126).

A partir da década de 70, começam a ser divulgados os estudos empreendidos entre os anos de 1919 e 1929 por um grupo de estudiosos russos, que passou a ser denominado como Círculo de Bakhtin. Este pequeno grupo formado por profissionais de diferentes áreas inaugurou uma nova forma de compreensão a respeito da interação através da linguagem, pois a compreendia como uma prática em funcionamento e não como um objeto estático e abstrato.

Tal perspectiva representou a passagem dos estudos da linguagem para o discurso, compreendido como as manifestações dos indivíduos em determinados contextos sociais. Isso significa considerar a linguagem como uma manifestação determinada por situações concretas: aquilo que é dito e escrito está condicionado a certos usos possíveis da linguagem e tem suas formas e conteúdos também determinados por certas condições histórico-culturais. Do mesmo modo, a maneira como se ouve ou se lê - e se atribui sentido - também está dentro de um campo de possibilidades determinado pelos usos possíveis da linguagem em condições concretas.

Neste sentido, a linguagem é compreendida como um campo de luta ideológica e não como um sistema monolítico, ou seja, não há linguagem (ou discurso, ou texto) que não esteja envolvida em relações sociais definidas que, por sua vez, são parte de sistemas políticos, ideológicos e econômicos. Por isso, "as palavras são multissignificativas, elas não têm um sentido congelado: são 
sempre as palavras de um sujeito humano específico a outro, e esse contexto concreto e prático dá forma a seu significado, fazendo-o variar" (EAGLETON, 2006, p. 175).

O texto, portanto, não pode ser considerado como um conjunto de signos que registra ou transmite ideias, pois, como forma de articulação da linguagem, ele não é tomado como uma unidade de sentido pré-estabelecido, da mesma forma que o autor não é considerado como sujeito de vontade absoluta, capaz de transmitir através do código escrito todos os seus pensamentos e ideias. Os sentidos inscrevem-se nos sujeitos, condicionados por determinados contextos, tanto na produção, quanto na recepção dos discursos. $\mathrm{O}$ ato de ler, então, é compreendido como uma relação dialógica entre os discursos do autor e os discursos do leitor, que interagem em contextos concretos (de produção e de recepção) para produzir sentidos.

A partir deste pressuposto, podemos afirmar que o sentido do texto não se esgota, porque é histórico. Ainda que um texto seja único, cada leitura é singular e compõe um novo diálogo, marcado pelas múltiplas vozes que constituem a interação autor-texto-leitor, configurando um novo "elo na cadeia da comunicação discursiva" (BAKHTIN, 2011, p. 299). Desse modo, o autor entende a compreensão como uma postura ativa de diálogo com o enunciado:

Compreender a enunciação de outrem significa orientar-se em relação a ela, encontrar o seu lugar adequado no contexto correspondente. A cada palavra da enunciação que estamos em processo de compreender, fazemos corresponder uma série de palavras nossas, formando uma réplica. Quanto mais numerosas e substanciais forem, mais profunda e real é a nossa compreensão (BAKHTIN, 2014, p. 137).

$\mathrm{O}$ ato de ler, portanto, não se coloca como uma prática passiva, mas como uma atividade interativa altamente complexa de produção de sentidos, uma vez que o leitor mobiliza outros discursos que entram nessa cadeia discursiva, como denomina Bakhtin, em relação às palavras materializadas no texto que, por sua vez, são lidas numa alternância ininterrupta de interação, ou seja, dialógica.

No seu diálogo com o texto, mediado por outros textos, o leitor singulariza sua compreensão. Nesse sentido, compreender não é encontrar o significado do texto dado pelo autor, mas construir essa compreensão a partir de si próprio, em diálogo com o texto: "Assim, a compreensão completa o texto: ela é ativa e criadora" (BAKHTIN, 2011, p. 378).

\section{O leitor como sujeito constituído na intersubjetividade}

Compreender o sujeito leitor como alguém que constrói significados sobre o que lê, com base em um contexto histórico-cultural exige também considerá-lo como um indivíduo que não existe por si e para si e que se autodefine a partir de um eu interior, mas como alguém que existe a partir das relações com o outro. Isto é, pressupõe que a subjetividade do ser humano é constituída socialmente, culturalmente, ou, em outras palavras, na intersubjetividade.

Bakhtin (2014), debatendo a questão da consciência individual, afirma que esta só pode se constituir no processo de interação social, que, por sua vez, se realiza de maneira mais clara e completa através da linguagem. Em outras palavras, é a interação através da linguagem que possibilita ao sujeito construir a consciência de si mesmo e compreender o mundo a seu redor:

Tudo o que me diz respeito, a começar pelo meu nome, chega do mundo exterior à minha consciência pela boca dos outros (da minha mãe, etc.), com sua entonação em sua tonalidade valorativa-emocional. A princípio eu tomo consciência de mim através dos outros: deles eu recebo as palavras, as formas 
e a tonalidade para a formação da primeira noção de mim mesmo" (BAKHTIN, 2011, p. 373-374).

Para Bakhtin (2014), a consciência do indivíduo sobre si mesmo não existe na interioridade, mas somente através da interação com o outro. É o diálogo com o outro que possibilita nossa compreensão sobre nós mesmos - e nossos pensamentos, ideias e posições também nascem nesse terreno interpessoal - para então se internalizarem e nos constituírem. Nesse sentido, a subjetividade humana é uma construção social. Constituímo-nos como indivíduos a partir das experiências e do contexto histórico e cultural no qual estamos inseridos. Assim, também podemos afirmar que:

Do nascimento à velhice, pensamos unicamente em resposta ao que nos foi lançado por outros (...) Sem o outro, não existe sujeito. Em outras palavras, o gesto de partilha ou da troca, a relação, está na origem mesma da interioridade, que não é um poço onde se mergulha, mas que se constitui entre dois, a partir de um movimento em direção ao outro. Está também na origem mesmo da identidade (se é que ela existe, o que pode ser discutido), que se constitui em um movimento simultaneamente centrífugo e centrípeto, em um impulso em direção ao outro (PETIT, 2009, p. 51).

Estendendo essa compreensão a respeito da formação social do sujeito para a interação entre o texto e o leitor, podemos afirmar que cada leitura é o encontro singular entre um texto e um leitor real, com uma história específica, experiências, emoções, interesses e gostos, constituídos na sua vivência única, e que interferem nas apropriações que ele faz do texto. Especialmente quando se fala do texto literário, defendemos, assim como Rouxel (2013b, p. 195), a impossibilidade de se ignorar o leitor real, uma vez que o investimento do leitor como sujeito é não só inevitável, mas também indispensável.

\section{O papel do leitor na leitura do texto literário}

Nessa mesma perspectiva, Lebrun (2013, p. 139) também explica o encontro do leitor com a obra literária como algo que se produz "por meio dos sentimentos, das emoções, das lembranças, das ideias que decorrem das experiências, dos saberes, e das representações pessoais que o leitor tem de si mesmo, do texto e do mundo" e que, por isso, essa leitura é sempre uma experiência singular, na qual o leitor está autorizado a exprimir suas impressões pessoais.

A essa apropriação pessoal e, portanto, singular $^{8}$, os autores franceses denominam como Leitura Subjetiva. Em outras palavras, podemos definir esta leitura como aquela em que um leitor real, empírico, se engaja na produção de sentidos em relação ao texto, permitindo-se afetar por ele. Não se trata, é claro, de considerar a subjetividade desse leitor como algo interior, psíquico, que brota da individualidade de um sujeito distanciado das condições culturais e sociais, nas quais está inserido. Trata-se, entretanto, de considerar a leitura realizada na existência singular de um sujeito real, em um ato único e irrepetível - para usar uma expressão de Bakhtin - porque decorre de condições concretas que o constituem e não poderiam ser repetidas na singularidade da experiência vivida por nenhum outro indivíduo.

Podemos dizer que, em se tratando do leitor de literatura, essa singularidade da experiência de leitura deve ser compreendida não como incidental, mas como uma necessidade.

8 Compreendemos a apropriação singular, nesse contexto, não como uma compreensão do texto necessariamente distanciada das interpretações aceitas socialmente, mas relacionada ao modo como o texto afeta cada leitor de maneira singular. 
Se, ao ler textos informativos ou técnicos, o leitor busca compreender seus aspectos mais formais e mais consensuais, na leitura de literatura, o leitor é convocado a ultrapassar estas exigências. Não basta fazer inferências e suposições e checá-las no decorrer da leitura, pois o texto literário é produzido com a intenção de conquistar um envolvimento pessoal do leitor.

Langlade (2013) explica que a leitura realizada por esse leitor eventualmente utiliza conhecimentos literários e estilísticos, mas se baseia, principalmente, em sua experiência de mundo, suas recordações pessoais, sua própria história. Nesse tipo de leitura, a atenção do leitor não está voltada para elementos relacionados a uma literariedade do texto, à códigos específicos da literatura (como gênero, intertextualidade, traços estéticos), mas a uma apropriação da obra para si.

Portanto, o investimento subjetivo do leitor, ou seja, a relação estabelecida por ele entre o texto e suas impressões pessoais, emoções e sentimentos, não se refere apenas a uma possibilidade, mas sim a uma necessidade funcional da leitura literária. Conforme ressalta Rouxel (2012, p. 281), "o investimento do leitor como sujeito é incontornável e necessário a toda experiência verdadeira de leitura".

Desta forma, a leitura cria um texto do leitor, pois este a realiza de forma a atender aquilo que lhe interessa de forma particular, se apropria da obra para responder às suas necessidades, de forma enraizada em sua experiência e, ao mesmo tempo, projeta nele seu mundo, seu modo de ver. O texto literário pode ser considerado como um espelho identitário, no qual se refletem os interesses conscientes ou inconscientes do sujeito leitor (ROUXEL, 2012).

Para exemplificar alguns modos como essa apropriação singular é feita pelo leitor, Rouxel (2013a, p. 172) destaca três procedimentos comuns dos leitores de literatura observados em sua pesquisa com alunos do ensino médio francês: i. o hábito de destacar e selecionar excertos ou citações, através dos quais o leitor retém na memória fragmentos do texto nos quais se reconhece, com os quais se identifica; ii. a prática de copiar trechos lidos, numa tentativa de se apropriar daquilo que foi lido, dizer o que não se pode ainda exprimir com as próprias palavras; iii. a tentativa de redizer o texto com suas próprias palavras por meio da atitude de compartilhar a leitura através de comentários ou resumos.

Tais procedimentos revelam maneiras como os leitores buscam se apropriar do texto literário de forma particular, não no sentido prático ou com fins imediatos, mas como uma forma de compreender e construir sua perspectiva pessoal a respeito do mundo e da própria existência através da leitura.

\section{Contribuições da abordagem da Leitura Subjetiva para a leitura de literatura na escola}

Sob a perspectiva apresentada, o trabalho com literatura na escola deve prezar oportunidades para que as crianças vivenciem experiências pessoais de leitura, essenciais na formação do leitor literário (mas também do leitor, de modo mais amplo). Entendemos que, para formar um sujeito leitor, de pouco adianta ler textos que discorram sobre a importância da leitura na sociedade atual, pouco importa também ouvir discursos sobre o prazer de ler ou mesmo participar de práticas pedagógicas que exaltem as qualidades do texto literário.

Para formar um sujeito leitor (e aqui é importante também destacar que, ao defendermos o papel da escola nessa formação, nos importamos muito mais com a divulgação de práticas que permitam experiências positivas da criança com o texto literário, do que com a criação de um mercado consumidor de livros - posições frequentemente tratadas de maneira indistinta ${ }^{9}$ ),

\footnotetext{
${ }^{9}$ Embora reconheçamos a necessidade das livrarias e do mercado editorial investirem seus esforços na ampliação do consumo de livros (por razões óbvias), entendemos que esse não é o papel da escola, mesmo porque consideramos, como explicaremos a seguir, que um sujeito leitor, muito mais do que um leitor idealizado, que supostamente lê em todas as épocas e circunstâncias de sua vida, é alguém capaz de se apropriar do texto literário
} 
acreditamos que a vivência de práticas significativas de leitura de textos literários na escola pode não só criar o gosto pela leitura de literatura, como também pela leitura de qualquer outro tipo de texto, inserindo essa prática em diferentes âmbitos da vida pessoal.

Do modo como compreendemos, esse sujeito leitor é alguém: capaz de fazer escolhas, ultrapassando modelos e práticas impostas, de modo a fazer opções de leitura de acordo com interesses e gostos pessoais (sempre considerando os condicionamentos históricos dessa pessoalidade). Um leitor apto a realizar uma leitura que, para além dos sentidos consensuais e mais superficiais, apropria-se do texto literário como uma forma privilegiada de conhecer a si mesmo e compreender o mundo a sua volta. Um leitor, enfim, capaz de se posicionar como parte integrante de uma comunidade de leitores, colocando em diálogo os sentidos produzidos por ele e aqueles compartilhados pelo grupo de leitores do qual faz parte.

Essa concepção de leitor como um sujeito interativo, que se apropria do texto, demanda um ensino voltado à leitura literária em contraposição a um enfoque baseado numa cultura literária. Explicita-nos Lebrun (2013, p. 138) que se trata "menos de ensinar a literatura do que de estabelecer um ensino-aprendizagem da leitura literária" (grifos nossos).

Ainda nesta direção, Rouxel (2013a) traz para o debate o próprio conceito de cultura literária, opondo-se à concepção clássica que a considera como patrimônio reconhecido ou cultura erudita, e valorizando o corpus de leitura de cada leitor, caracterizado pela heterogeneidade e pelo valor simbólico pessoal. Para ela:

A essa concepção tradicional de cultura, que permite avaliar, em vista de referências comuns, o grau de cultura dos indivíduos, se opõe uma concepção às vezes mais liberal e às vezes mais empírica relacionada a um olhar menos exterior. A cultura literária não é esse absoluto, esse ideal em direção ao qual deve tender o sujeito, mas um espaço simbólico composto às vezes de referências comuns e outras vezes de referências pessoais reconfiguradas por sua subjetividade. Ela não é uma abstração, lugar de um consenso ilusório, mas um conjunto limitado e móvel de dados concretos, marcados pela singularidade do sujeito e constituindo-a (ROUXEL, 2013a, p. 168).

Outro destaque da autora concerne à cultura literária compreendida como corpus estabelecido a partir da crítica especializada, que categoriza a literatura como um todo ordenado, coerente e único. Sua defesa é por um paradigma de cultura literária mais funcional, podendo ser constituída a partir das leituras múltiplas realizadas pelo leitor, tanto de obras reconhecidas, como daquelas que têm valor pessoal.

Tal abordagem traz consigo a discussão sobre os papéis do professor e do aluno, considerando a necessidade de que ambos renunciem às posições absolutas em relação à leitura, impostas pela convenção social/escolar e tomadas como imutáveis. Para a autora, é necessária outra atitude frente à leitura de literatura na escola que, a partir da recepção do aluno, o convide à aventura interpretativa com sua complexidade e riscos, reforçando suas competências através do diálogo com o texto e com os pares.

Rouxel (2013a) ainda defende que a cultura literária deve ser considerada a partir do percurso singular de cada leitor, conjugando saberes conceituais e experienciais, conhecimentos tradicionais e singulares, apropriações históricas e pessoais. Tal perspectiva "enraiza a cultura literária na experiência do sujeito: se desejamos que a cultura literária seja efetiva - ativa - (e

para si, quando sentir interesse ou necessidade de fazê-lo. Assim, pode ser considerado um sujeito leitor mesmo aquele que, por qualquer razão, não lê com assiduidade. 
não uma simples finalidade do ensino), importa que a leitura seja para o aluno um acontecimento" (ROUXEL, 2013a, p. 178).

Tal discussão acerca da leitura literária, singular e pessoal, inscreve-se numa abordagem mais atual no campo educacional e explicita uma concepção de ensino-aprendizagem, que privilegia o processo em detrimento do produto final (o resultado), como já defendia Vigotski (1998). O foco privilegiado da relação de ensino é o aluno e não o professor, que transmite sentidos convencionados e imutáveis.

O trabalho pedagógico nessa perspectiva tem implicações complexas: é preciso que as práticas de leitura realizadas em sala de aula se desloquem de um enfoque objetivo e consensual para um enfoque que acolha as apropriações singulares dos alunos; é preciso também compreender a cultura literária como um conjunto de saberes com significado para o sujeito leitor, ultrapassando uma concepção de cultura literária como acúmulo de saberes legitimados, "eruditos"; é preciso ainda ultrapassar a ideia do ensino de literatura, estabelecendo um trabalho pedagógico que privilegie a experiência pessoal de leitura literária.

Se entendermos, conforme afirma Bakhtin (2011), que a palavra preenche distintas funções ideológicas, configurando enunciados concretos, os quais refletem/refratam nuances em termos de posições e valores, e reconhecermos a experiência da leitura de literatura como atividade simbólica constitutiva da subjetividade (OMETTO, CRISTOFOLETI, 2012), entendemos também que o modo como se proporciona a leitura literária na escola revela concepções referentes tanto à prática docente, como também com relação ao papel da literatura, da leitura e da própria escola na sociedade.

Para finalizar, mas não para terminar, o modo como definimos a importância, o valor da leitura de literatura (e aqui incluímos a nós, que escrevemos esse texto) corresponde a um contexto histórico cultural e reflete posicionamentos ideológicos e políticos. Ao defendermos a experiência da leitura literária como forma de proporcionar a abertura à diversidade, à reflexão, ao autoconhecimento, à compreensão de si e do outro, à percepção de modos de pensar, sentir e agir, próprios e dos outros, defendemos que essa experiência ocorra em contextos que se abram à pluralidade de sentidos, uma defesa viável e necessária para o contexto escolar.

\section{Referências}

BAKHTIN, Mikhail Mikhailovich. Estética da criação verbal. Prefácio de Tzvetan Todorov; Introdução e tradução do russo de Paulo Bezerra. $6^{\text {a }}$ ed. São Paulo, SP: WMF Martins Fontes, 2011.

BAKHTIN, Mikhail Mikhailovich. Marxismo e filosofia da linguagem: problemas fundamentais do método sociológico na ciência da linguagem. Tradução de Michel Lahud e Yara Frateschi Vieira; Prefácio de Roman Jakobson; Apresentação de Marina Yaguello. 16. ed. São Paulo, SP: Hucitec, 2014. 203 p. (Linguagem e Cultura; 3).

EAGLETON, Terry. Teoria da literatura: uma introdução. Tradução de Waltensir Dutra. 6. ed. São Paulo, SP: Martins Fontes, 2006. 387 p. (Biblioteca Universal).

LANGLADE, Gérard. O sujeito leitor, autor da singularidade da obra. Tradução: Rita JoverFaleiros. In: ROUXEL, Annie; LANGLADE, Gerard; REZENDE, Neide Luzia de. (Org.) Leitura subjetiva e ensino de literatura. Tradução de Amaury C. Moraes et al. São Paulo, SP: Alameda, 2013. p. 25-38. 
LEBRUN, Marlène. A emergência e o choque das subjetividades de leitores do maternal ao ensino médio graças ao espaço interpretativo aberto pelos comitês de leitura. Tradução: Gabriela Rodella de Oliveira. In: ROUXEL, Annie; LANGLADE, Gerard; REZENDE, Neide Luzia de. (Org.) Leitura subjetiva e ensino de literatura. Tradução de Amaury C. Moraes et al. São Paulo, SP: Alameda, 2013. p. 133-148.

OMETTO, Cláudia B. de C. Nascimento; CRISTOFOLETI, Rita de Cássia. A leitura de literatura como possibilidade de formação. Leitura: Teoria \& Prática, Associação de Leitura do Brasil, ano 30, n. 58, p. 1843-1851, jun. 2012.

PETIT, Michèle. A arte de ler: ou como resistir à adversidade. Tradução de Arthur Bueno e Camila Boldrini. São Paulo, SP: Editora 34, 2009. 304 p.

PETIT, Michèle. Leituras: do espaço íntimo ao espaço público. Tradução de Celina Olga de Souza. São Paulo, SP: Editora 34, 2013. 168p.

ROUXEL, Annie. Práticas de leitura: quais rumos para favorecer a expressão do sujeito leitor? Tradução de Neide Luzia de Rezende e Gabriela Rodella de Oliveira. Cadernos de Pesquisa, v. 42, n. 145, p. 272-283, jan./abr. 2012.

ROUXEL, Annie. Apropriação singular das obras e cultura literária. In: ROUXEL, Annie; LANGLADE, Gerard; REZENDE, Neide Luzia de. (Org.) Leitura subjetiva e ensino de literatura. Tradução de Amaury C. Moraes et al. São Paulo, SP: Alameda, 2013a. p 165-189.

ROUXEL, Annie. O advento dos leitores reais. In: ROUXEL, Annie; LANGLADE, Gerard; REZENDE, Neide Luzia de. (Org.) Leitura subjetiva e ensino de literatura. Tradução de Amaury C. Moraes et al. São Paulo, SP: Alameda, 2013b. p 191-208.

ROUXEL, Annie; LANGLADE, Gerard; REZENDE, Neide Luzia de. (Org.) Leitura subjetiva e ensino de literatura. Tradução de Amaury C. Moraes et al. São Paulo, SP: Alameda, 2013. 210p.

VIGOTSKI, Lev Semenovich. A formação social da mente: o desenvolvimento dos processos psicológicos superiores. Coautoria de Michael Cole. 6. ed. São Paulo, SP: Martins Fontes, c1998. 191p. (Psicologia e pedagogia).

\section{Sobre as autoras}

Cláudia de Oliveira Daibello. Atualmente é Chefe do Departamento de Normas Pedagógicas na rede municipal de Ensino de Santa Bárbara d'Oeste, na qual ingressou no ano de 2002 como professora de Ensino Fundamental. Doutoranda no PPGE da Faculdade e Educação UNICAMP (2015-). Membro do grupo ALLE/AULA com pesquisas que abordam a relação entre literatura infantil e escola e a formação do leitor.

E-mail: claudiadaibello@yahoo.com.br.

Cláudia Beatriz de Castro Nascimento Ometto. Professora no PPGE da Faculdade de Educação da UNICAMP. Pesquisadora da linha Linguagem e Arte em Educação no Grupo de Pesquisa Alfabetização, Leitura, Escrita e Trabalho Docente na Formação de Professores 
A LEITURA PESSOAL DE LITERATURA NA ESCOLA COMO POSSIBILIDADE DE FORMAÇÃO DO...

(ALLE/AULA), atuando principalmente nos seguintes temas: leitura, escrita, alfabetização, salas de leitura, formação de professores, práticas de ensino.

E-mail: cbometto@yahoo.com.br. 